\title{
3. CONVERSACIONES
}

3. Conversations

\section{CONVERSACIÓN CON JOAQUÍN DÍAZ. ETNÓGRAFO}

\section{Conversation with Joaquín Diaz. Ethnographer}

\author{
Santiago Esteban Frades \\ Universidad de Valladolid \\ Correo-e: s.estfrasa@gmail.com \\ Carmen Romero URUeÑa \\ Universidad de Valladolid \\ Correo-e: romurema@gmail.com
}

Recepción: 25 de junio de 2019 . Envío a informantes: 2 de julio de 2019

Aceptación definitiva: I8 de septiembre de 2019

U

NA TARDE FRÍA DE INVIERNO DE 20I9, desapacible en el campo inmenso de trigales todavía encogidos que nos rodea. Nos encontramos en el pueblo medieval amurallado de Urueña (Valladolid), en la sede de la Fundación Joaquín Díaz, en un espacioso y sugerente salón-biblioteca, cargado de libros y motivos del folklore musical y popular. Nos acoge con total afabilidad nuestro interlocutor y presidente de mencionada Fundación, previa cita acordada con anterioridad.

Joaquín Díaz González (Zamora, 1947), como escuchamos a través de sus propias palabras, es un estudioso de lo más profundo de la antropología y la etnografía popular desde hace varias décadas. Es un etnógrafo ampliamente reconocido y valorado en el estudio de la cultura popular occidental. Sus publicaciones sobre folklore, canciones, catálogos de exposiciones, discos, programas de televisión, museos de música e instrumentos musicales populares, colecciones de pliegos de cordel son siempre tenidas en cuenta en cualquiera de los estudios sobre antropología popular, en España y en otros países occidentales. Fue pionero en este tema desde los años I970, y es hoy una autoridad indiscutible en el mundo en el tema que nos ocupa, más allá de su afectuosa sencillez y capacidad de acogida, propias de la humildad de los sabios.

Para muchas de las cuestiones que nos ocupan a los historiadores de la educación, la ingente obra de Joaquín Díaz es un ejemplo de laboriosidad eficaz, de 
metodología científica bien aplicada, de resultados espectaculares para la cultura y la educación popular, y su estudio genético e histórico. Dispuestos a realizar la inmersión en al ámbito de la antropología popular y los métodos etnográficos de la mano y las palabras de Joaquín Díaz.

P. Podemos empezar esta conversación repasando aspectos de tu trayectoria profesional. ¿Cómo te iniciaste en el mundo de la etnografía, de la música, de la cultura popular, del amor por las tradiciones y el folklore?

R. Mi interés por lo popular comenzó en casa, mi madre era pianista y la música siempre estaba presente. Mi madre nos cantaba canciones cuando éramos pequeños y mi abuelo nos contaba cuentos. Siempre había relación con el pasado aunque no tenía que ver directamente con el patrimonio cultural, pues era más bien una diversión. Me acuerdo de muchas cosas que mi madre decía o contaba y eso ha quedado en mí como el principio de todo mi amor por la música y lo popular. Luego decidí, cuanto tenía dieciséis años, formar un grupo musical de canción folk con compañeros del colegio y ese fue el veneno que tuve siempre, antes que los estudios y cualquier otro tipo de actividad; de hecho, mis padres siempre se quejaban de que cantaba más que estudiaba. Dejé rápidamente el grupo porque nos presentamos a un programa de televisión que no tuvo mucho éxito y entonces decidí ir a Madrid ya que era la única salida posible en esa etapa. A partir del año 1968, es cuando grabo mi primer disco, aunque esa etapa solo dura hasta 1974, que es cuando dejo de cantar. Pero cuando actuaba en público (recitales en colegios mayores, institutos, etc.), fui viendo que me gustaba explicar el contexto de las cosas, por qué se había producido esa canción y eso me llevó a investigar si las versiones que había recogido o leído en algún cancionero tenían un pasado, una correspondencia y, a partir de ahí, me fue entrando la curiosidad por descubrir

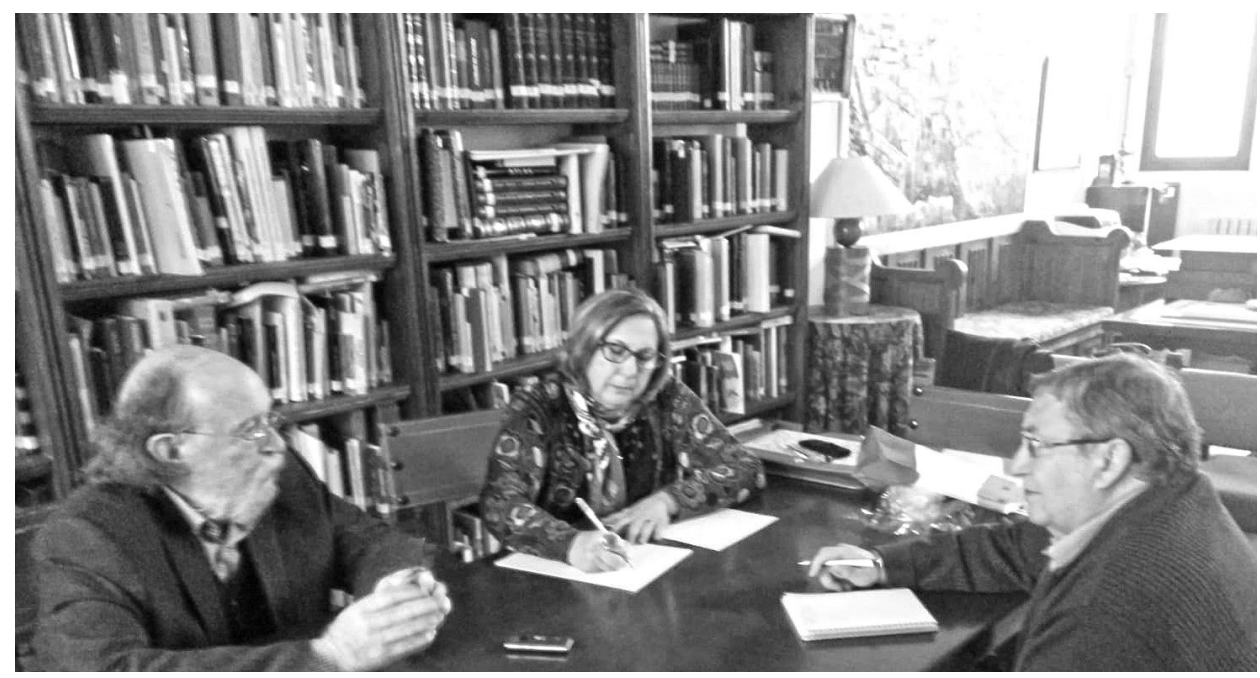




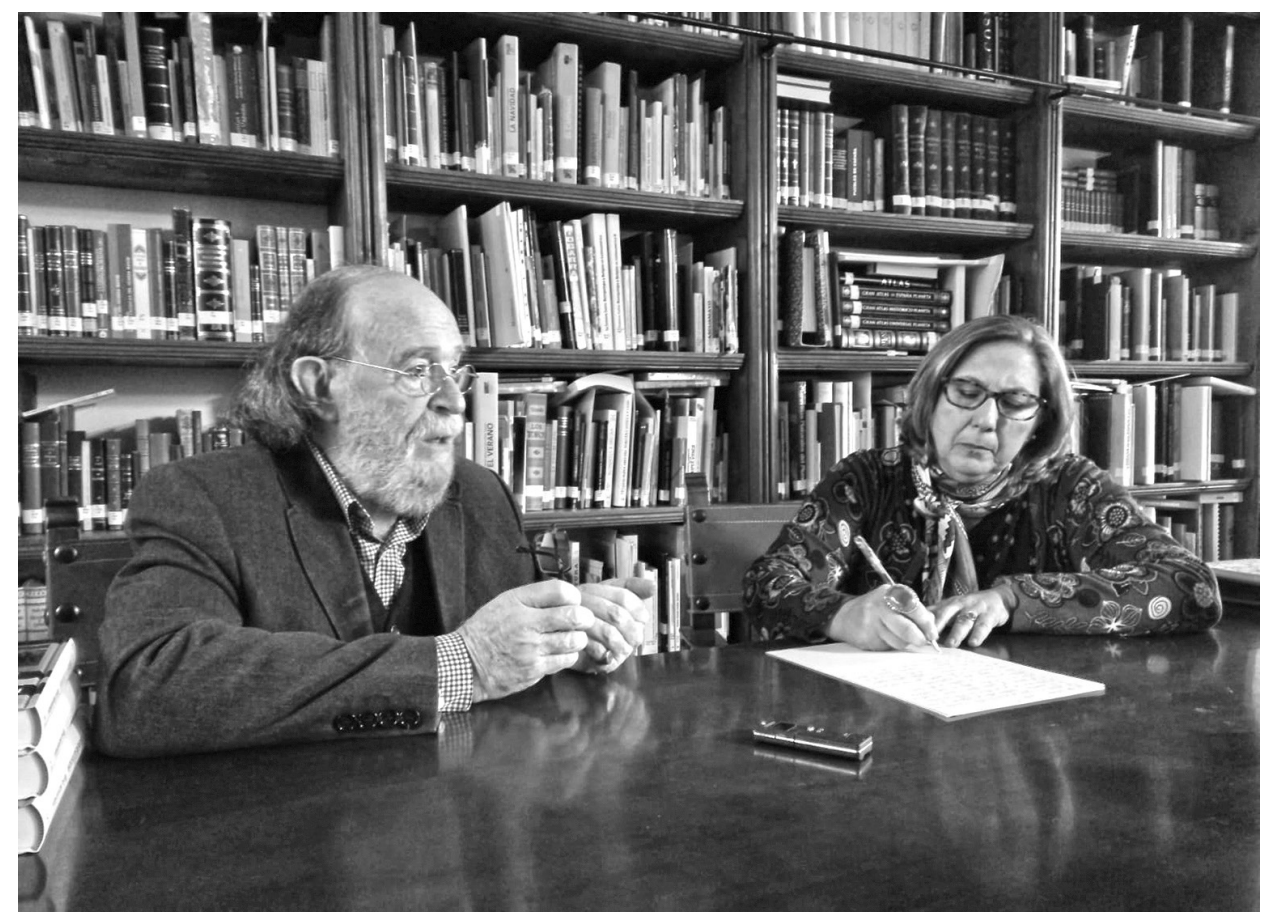

más de ese repertorio que cantaba y la vocación por la investigación y difusión de la música popular y la cultura tradicional. Es, por tanto, a partir de 1974, cuando me intereso por la etnografía y empiezo a trabajar las grabaciones y el trabajo de campo necesario para los etnógrafos y antropólogos, y es cuando empiezo a ir preguntando por los pueblos y a rastrear en la memoria de la gente lo que me pudieran comunicar. Me pasé unos años realizando trabajo de campo para recopilar tradiciones populares (canciones, romances, refranes, historias, fiestas, danzas, artesanía, trajes, etc.). Siempre diré que, recorriendo los pueblos de Castilla y León y hablando con las personas mayores, pasé los años más bonitos de mi vida.

\section{P. En esos momentos ¿tenías alguna relación con la universidad?}

R. No, en los años 70 la universidad era difícil; yo, de hecho, salí de la universidad sin licenciarme en nada, probablemente porque estaba decepcionado de no encontrar lo que a mí me gustaba, pensaba que hacer una carrera era perder el tiempo, y decidí dedicarme a la música más que a los estudios. Luego sí han surgido departamentos universitarios especializados en la antropología cultural; en 1993 , se crea la cátedra en la Universidad de Valladolid de «Estudios sobre la Tradición», pero yo, en aquella primera época, no encontré nada; mi relación con la universidad fue con los estudiantes, pues del 68 al 7I, rara era la semana que no cantaba en algún Colegio Mayor. 
P. El repertorio de publicaciones que tienes es muy amplio, desde la investigación y divulgación del romancero tradicional, pasando por la literatura de cordel y romances de ciego hasta diversos temas de carácter popular, e incluso temas sefardíes. ¿Podríamos decir que ha sido un proceso de aprendizaje que se produce de manera autónoma y autodidacta?

R. Autodidacta, siempre he leído mucho, por ejemplo Ramón Menéndez Pidal o Julio Caro Baroja es como si hubieran sido mis maestros; con Julio coincidí y he tenido cierta relación, con el otro por edad no, pero he estado en contacto con la Fundación Menéndez Pidal, con Diego Catalán. He tenido siempre una buena relación con el mundo académico y me he cuestionado cosas que se habían aceptado sin más. Así he construido mi propio pensamiento y he ido haciendo mi propia teoría a partir del descubrimiento de la parte práctica con la parte humana de la antropología. Cuando comencé a trabajar, la música popular tenía un sentido de anonimato, lo popular era aquello que no tenía autor, pero investigando, a veces, los he encontrado; de hecho, considero autor a la persona que te informa de los materiales que luego usamos, esa persona es alguien que tiene un sistema heredado o propio que le permite conocer el estilo del que él toma sus técnicas, sus textos o sus melodías para luego transmitirlo. El proceso empieza por el interés de una persona por cuestiones que le llaman la atención, le parecen curiosas, le gustan y

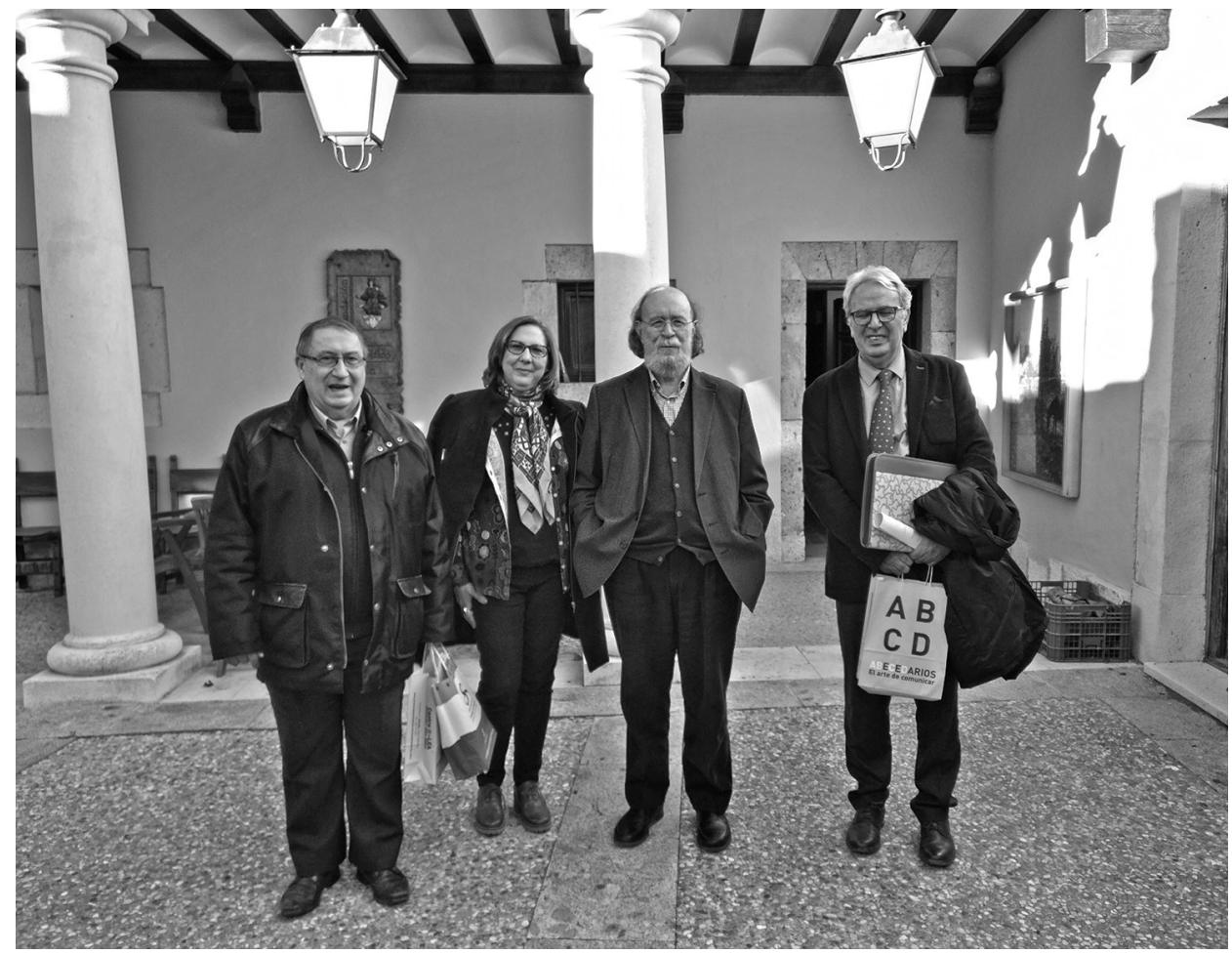




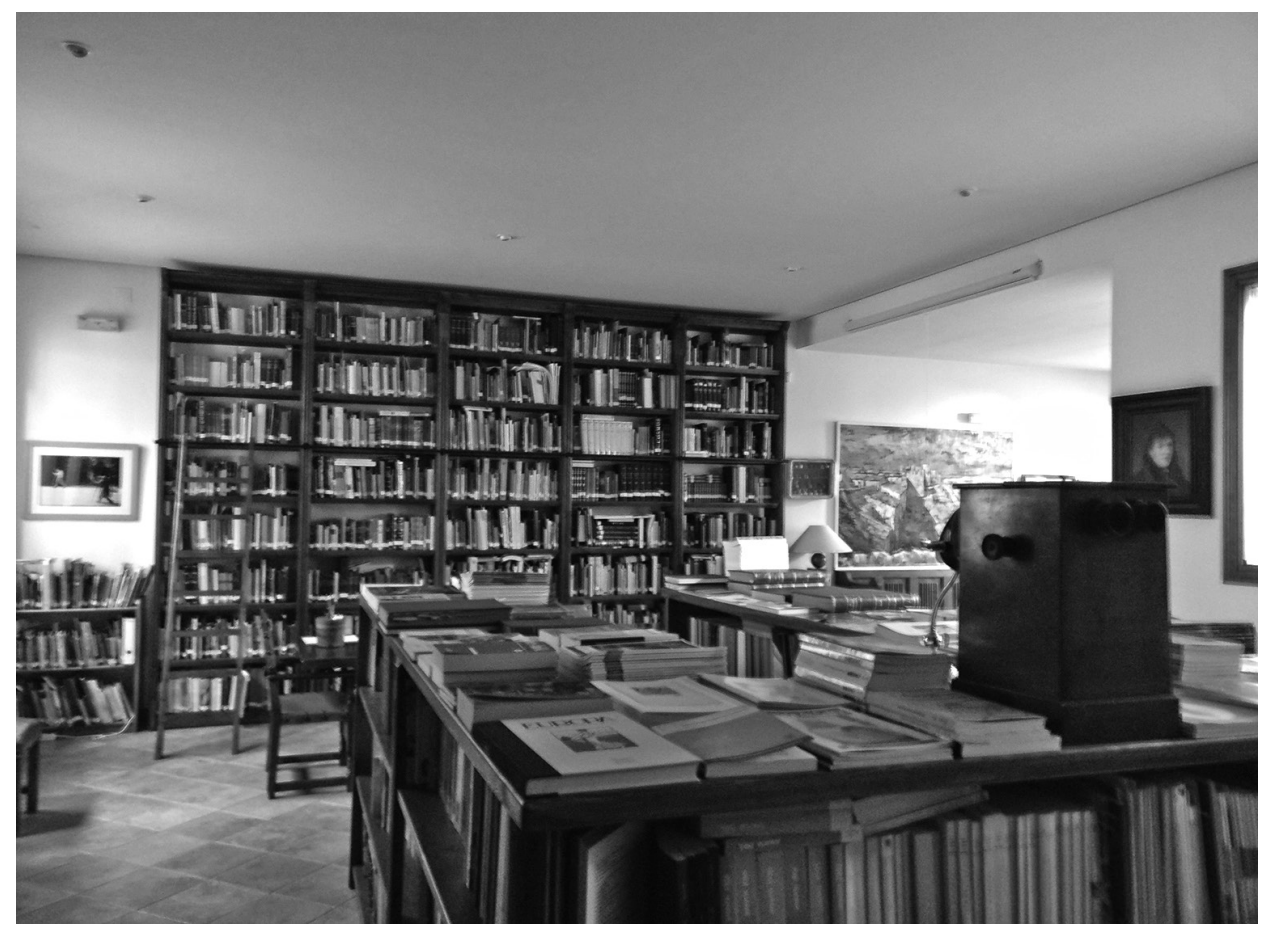

generan un repertorio anónimo, pero yo prefiero considerar que hay un esfuerzo, una habilidad y, en definitiva, un método que empieza por una persona interesada en estos temas de la tradición y del patrimonio, y lo que le lleva a crear su propio mundo y a tratar de transmitirlo; el proceso continúa cuando es capaz de comunicarlo para que los demás reciban esa información. Yo creo que esa persona tiene un gran mérito, no solo porque está en contra de lo que pasa generalmente, que es ir abandonando las cosas, sino porque además ha creado un camino propio.

P. Por lo tanto, desde una primera aproximación a la música de manera familiar, luego juvenil, vas enfocándote hacia la hermenéutica de los procesos de la antropología, de los condicionantes musicales, de quiénes son los intérpretes, del contexto. Eso lo explicas bien en el libro La memoria permanente. Reflexiones sobre la tradición.

R. Siempre he tenido la fortuna de combinar ambas vertientes, la práctica (yo mismo cantaba) y las preguntas que me iba haciendo ¿qué pensaría un autor para que se conociera lo que hace? Parto de la base de que a cualquier artista, a cualquier autor le interesa que haya un público (entendiendo por tal a cualquier personaje que en un pueblo era capaz de comunicar cosas y por tanto su trabajo tenía un sentido artístico). Siempre hay algo propio en el artista aunque se herede de otros personajes que han hecho antes lo mismo. Y si nos vamos hacia atrás en 
el tiempo, probablemente llegaríamos hasta la Edad Media o antes incluso porque siempre los sistemas de comunicación han sido parecidos: el juglar que cantaba en la plaza pública, el trovador, el buhonero que iba vendiendo estampas religiosas, etc. Todo eso crea un mundo que, en general, se ha estudiado poco a pesar de que ha tenido mucha importancia.

P. Lo que cuentas tiene que ver con un mundo pedagógico y formativo que se observa perfectamente en las obras que has editado de Canciones y cuentos tradicionales, Cien temas infantiles y, en particular, las publicaciones dedicadas a la literatura del cordel y romances de ciego: Romances de ciego, Coplas de ciego. Antología y Pliegos de Cordel, El ciego y sus coplas y Las ilustraciones en los pliegos de cordel.

R. Por supuesto que sí. La persona que trata de comunicar algo tiene, primero, que aprender el sistema para hacerlo y, segundo, ser eficaz para que le sigan. Esto va creando una escuela que luego se transmite y sirve a otros. Es el caso del mundo de los ciegos que llevaban los papeles para venderlos, y ahí se ve claramente cómo se han ido transmitiendo los mensajes desde hace muchísimo tiempo. Los ciegos, probablemente desde la Edad Media, ya estaban involucrados en ese mundo de comunicación, seguramente, porque les interesaba. Hay que recordar que había unas leyes muy estrictas en la Edad Media hacia los vagabundos, los pobres... estos colectivos estaban muy constreñidos siempre por normas.

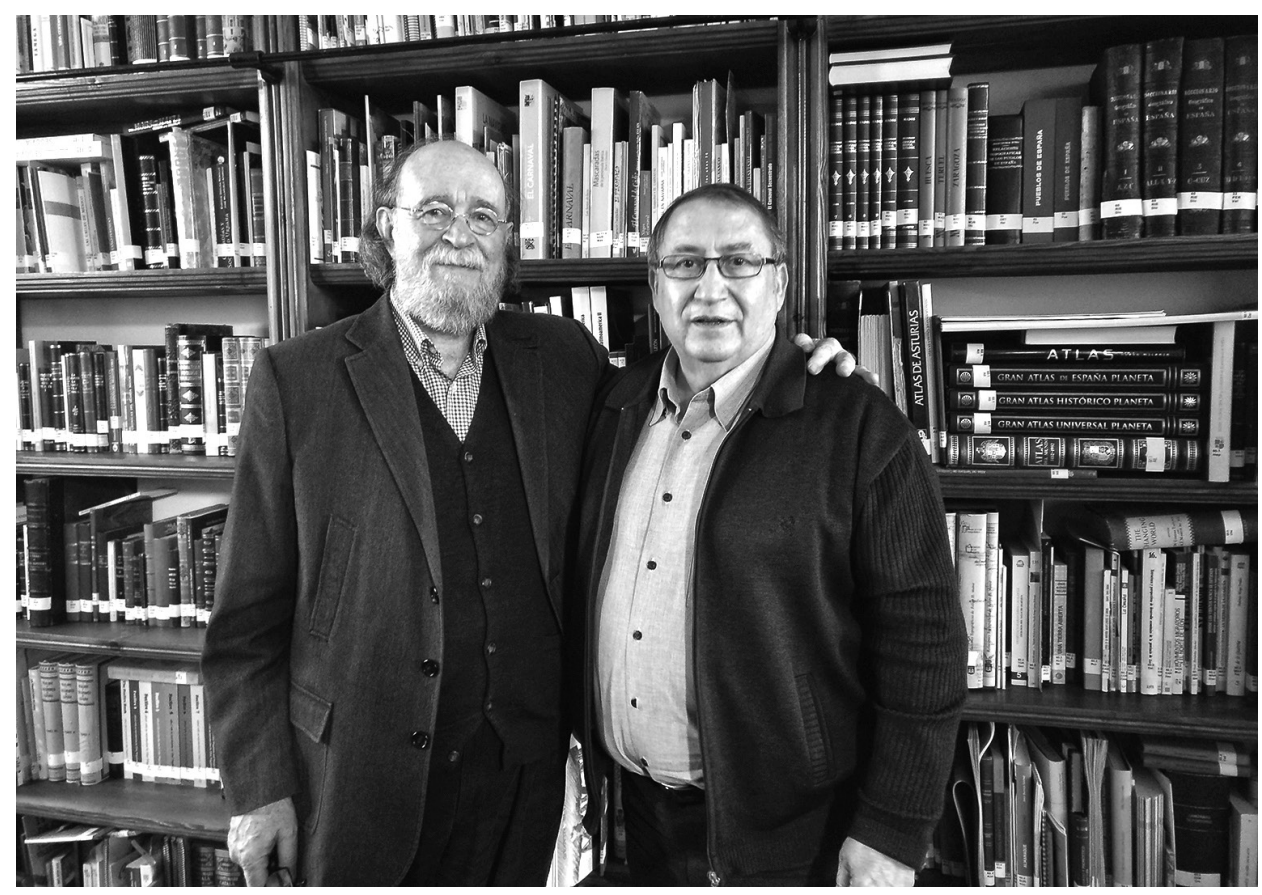

(C) EDICIONES UNIVERSIDAD DE SALAMANCA

Hist. educ., 38, 2019, pp. 391-404 


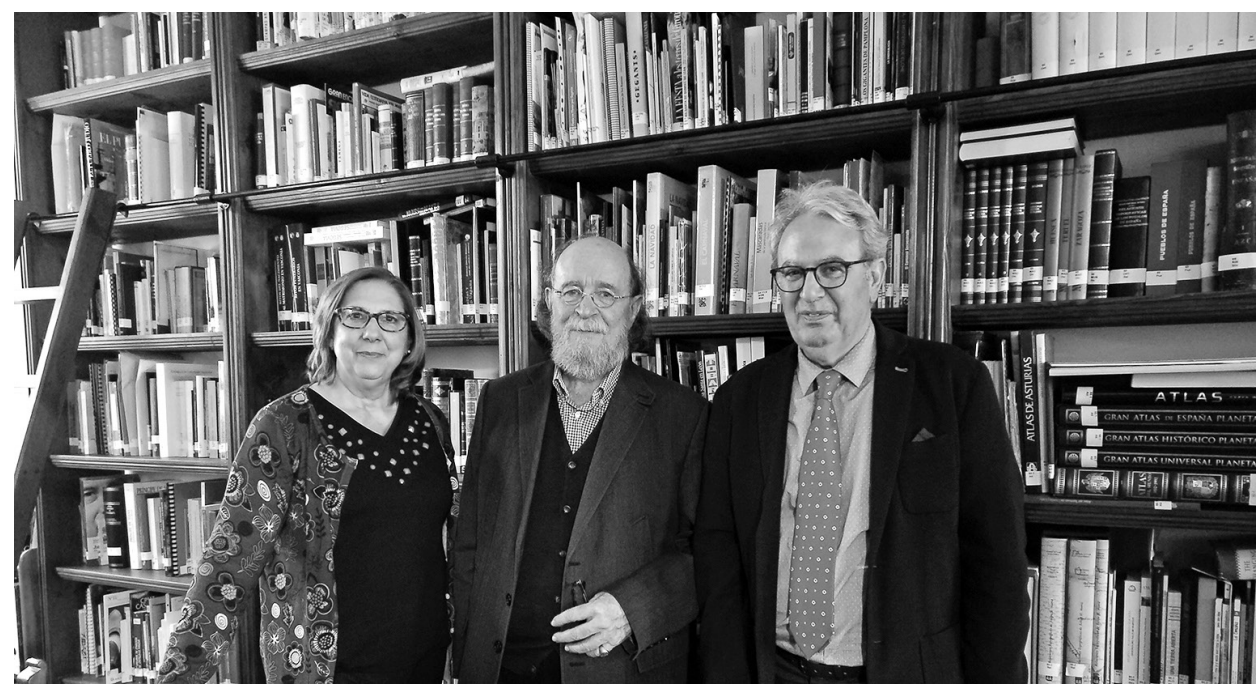

Los ciegos preferían tener un espacio más amplio y consiguieron de distintos reyes privilegios para poder vender, con lo cual se convertían en comerciantes, ya no eran mendigos, pasaban a otro estatus y una vez que se convertían en comerciantes había que buscar el sistema para que lo que querían transmitir se pudiera vender en un papel, papel que había que imprimir.

P. Es un tema apasionante y poco explorado, pero sabemos que en este Museo de Urueña se encuentra una de las mejores colecciones de Romances de Ciego de todo Occidente.

R. No lo sé, ahora mismo ya pasan de siete mil papeles. A través del estudio de esos documentos, en cada uno de los siglos, aunque hay alguna variación, se va comprobando que el ciego se comporta igual y sabe qué es lo que tiene que vender. Aparte de ese sentido comercial, hay que apreciar en él dos aspectos que en general no se han estudiado mucho. Uno es una cierta valentía y osadía para contar cosas que se le permitían decir por su discapacidad y otra es el sentido artístico que tenía la mayoría. Por lo tanto, estamos hablando de personas con sentido poético y musical.

P. ¿Es un fenómeno occidental o existe en otras culturas?

R. También se encuentra en otras culturas, pero no sé si se transmite a través del papel. El hecho del papel en España no es diferencial con otros países de Europa, pero sí lo es el que sean ciegos quienes producen y venden las coplas y romances. No siempre eran ciegos en otros países, eran vendedores ambulantes de alfileres, cintas para el pelo, etc., y al mismo tiempo de papeles, de estampas de santos con una oración que se cantaba o recitaba; era casi un oficio que se 
representa muy bien en grabados franceses del siglo XVIII y XIX, los oficios de la calle.

\section{P. ¿Eran educadores?}

R. Creo que sí, aunque el sentido didáctico y moral era muy particular. Educadores lo eran. De hecho, me ha contado mucha gente mayor que de pequeños, como no tenían la «perrita» para comprar el papel, seguían al ciego toda la mañana hasta que se aprendían el romance. Se supone que esos niños no iban a la escuela y se aprendían así los crímenes más truculentos que luego ellos también contaban.

P. ¿Podemos decir entonces que más bien eran una especie de educadores de calle?

R. Con sentido estético y moral; algunas veces se ajustaban a la moral católica, otras estaban en contra, y lo mismo pasaba con las ideas políticas; un ciego podía defender a la reina Isabel II y otro estar completamente en contra. En un vaciado que hice del periódico El Norte de Castilla sobre noticias de interés de esta temática, encontré, por ejemplo, que se narraba que un ciego había comenzado, en una posada o taberna, a discutir por razones políticas, y era curioso porque casi siempre ganaban los ciegos por astucia.

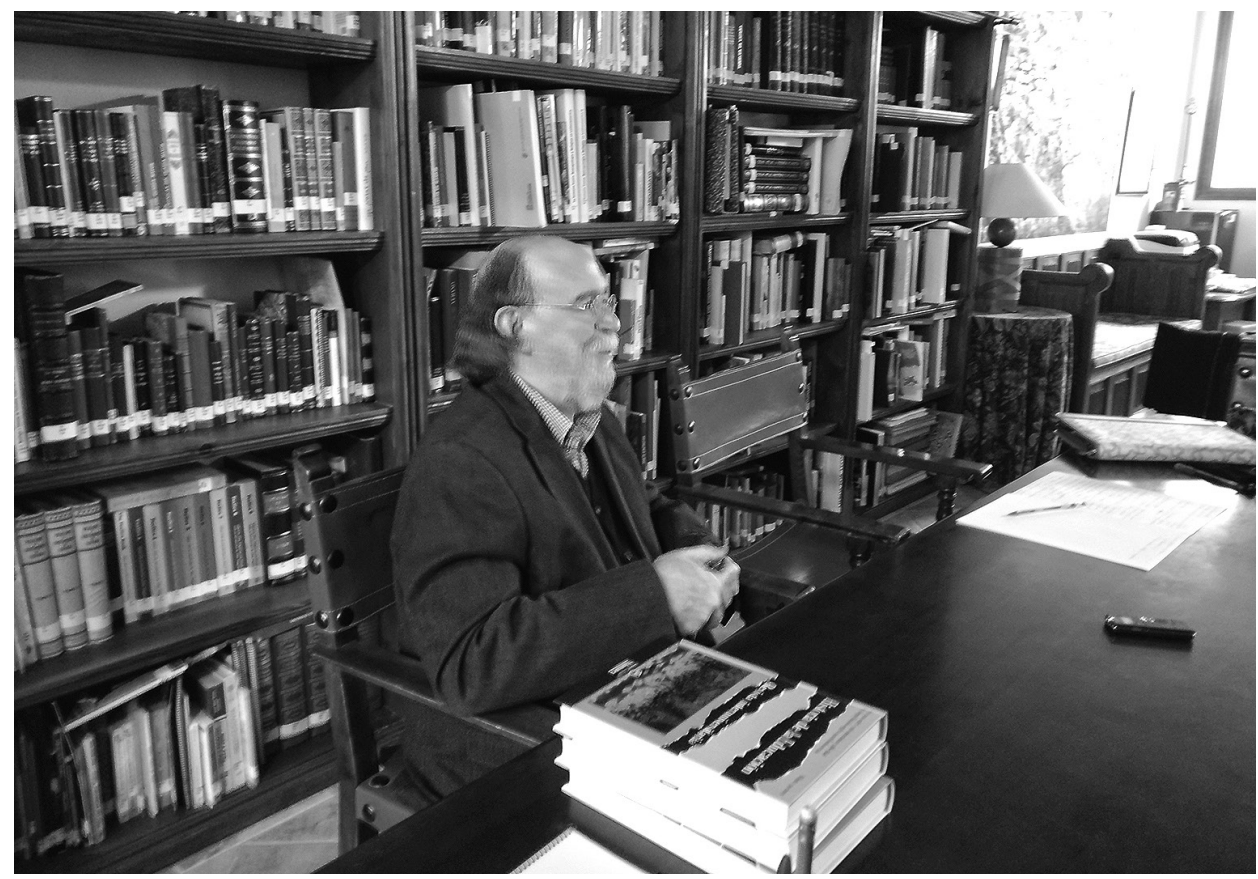




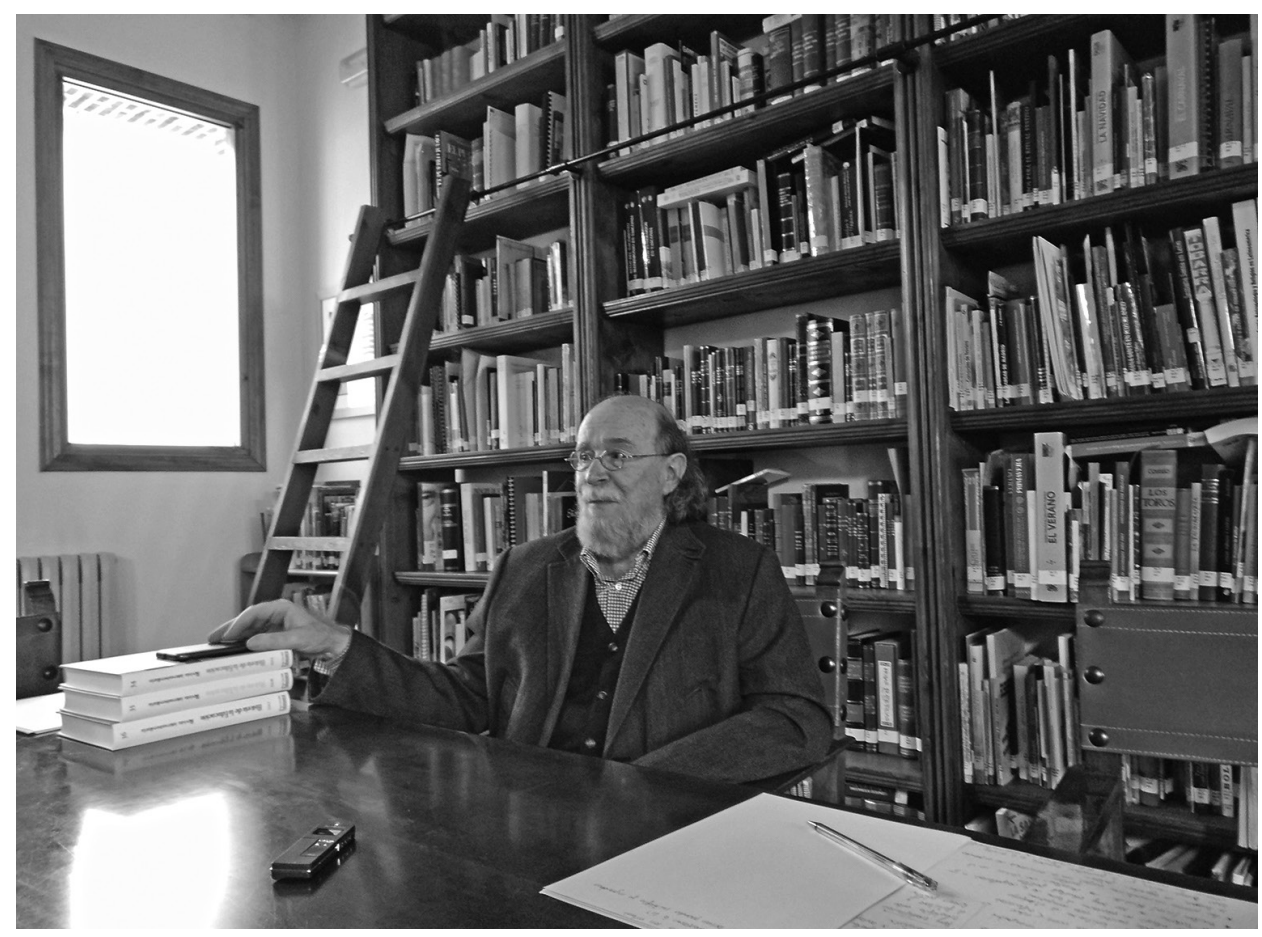

P. Hay muchos trabajos científicos, tesis doctorales, etc., relacionados con los romances de ciego. ¿No es cierto?

R. Sí cada vez más. El problema es que ahora hay más interés por ello, pero hay menos oportunidades de entrevistar a quienes tenían la clave de estas cosas. A mí me vino muy bien, por ejemplo, hablar con un impresor que trabajó en la calle Rodas en Madrid, en pleno Rastro, pues era el que hacía los papeles de ciegos en los últimos años. El encuentro se produjo a raíz de salir en el programa de televisión La clave de José Luis Balbín que me preguntó sobre mi trabajo y al comentarle que estaba recogiendo papeles de las coplas populares, tipo Juanita Reina, que se consideraban como una especie de subcultura, este hombre de la imprenta, Ataúlfo Rodríguez del Llano, al escucharlo, me escribió y me comentó que había terminado de cerrar la imprenta por lo que me dio dos maletas llenas de pliegos; ese fue el germen de todo lo demás, aunque yo ya tenía algo recopilado. Al revisar todo ese material se comprueba que están todos los papeles sellados por la censura desde el año 1936 hasta el cincuenta y tantos, a pesar de que este hombre buscaba caminos para burlarla.

Otra cuestión era imprimir cosas que tuvieran interés para el público. Los textos tenían que tener cierto morbo, pues igual que ahora la gente ve en la televisión los programas de «cotilleo», entonces interesaba saber por qué habían sucedido ciertos acontecimientos sociales, como, por ejemplo, por qué fulanito había 
matado a la novia, etc. Esa curiosidad está muy unida al ser humano y de eso se aprovechaba este tipo de literatura. Todo este mundo siempre me ha parecido muy interesante porque es muy popular y ha contado con agentes que trabajaban en favor de la difusión. En el fondo, se generaba una industria y un deseo de comunicar lo que ocurría en la vida.

P. No había otros instrumentos de radio, ni de televisión. Era un vehículo de transmisión de valores, de formas de pensar, de noticias.

R. Era curioso porque los ciegos, de algún modo, estaban esperando a saber las últimas noticias del gobierno de turno. Ellos tenían un sistema muy bien estructurado, pertenecían a cofradías (por ejemplo, a la de Santa Lucía) que permitían que los mayordomos organizaran dónde se situaban los ciegos en las ciudades en función de los puntos de más venta. Esto no se ha estudiado mucho, sin embargo, está claro que para que se produjera la venta de una noticia o de un romance había alrededor una infraestructura bien organizada.

P. Hasta ahora hemos estado hablando de la educación de calle y algunos aspectos de la educación popular, pero para completar ¿qué opinas de la presencia de lo popular y de lo etnográfico en el contexto escolar y en estudios en relación con la pedagogía?

R. Esta Fundación es el resultado de esa búsqueda de materiales que traté de perseguir en la universidad y no encontré; siempre pensé que hacer un Centro de Documentación vendría muy bien. Así comenzamos en un despacho que nos dejó la Diputación en Valladolid, en 1982, y se llamaba Centro Etnográfico de Documentaciones. El proyecto era buscar y proporcionar documentación para el profesorado que se daba cuenta de que había un retroceso del interés por los temas populares que eran prácticos para ellos. Lo primero que hicimos fue una colección de 20 libritos con temas que podían servir a un profesor para trabajar, títulos como Teatro popular, Danzas de palo, Arquitectura tradicional, Juegos de niños y mayores, Papiroflexia, La matanza del cerdo, Rollos jurisdiccionales, etc. Muchas de estas ideas me venían de los propios profesores. Después nos trasladamos a Urueña donde se habilitó esta Casona de la Mayorazga, edificio propiedad de la Diputación y, en 1991, se crea el Centro Etnográfico Joaquín Díaz, que se transforma en una Fundación.

\section{P. ¿Ese filón sigue vivo?}

R. No, porque ya han salido muchas más cosas. Cuando nosotros empezamos lo tuvimos que hacer sin una editorial que nos apoyara, lo tuvimos que hacer nosotros mismos. Faltaba el interés de las editoriales por sacar este material. Solo una se interesó cambiando el formato y ya perdimos el control sobre ello. Además, nos vinimos aquí (a Urueña) y tuvimos otras actividades que hacían imposible dedicarnos a todo. 


\section{P. ¿En qué año os vinisteis aquí?}

R. En el 87 me lo propusieron, una tarde de verano. El presidente de la Diputación me dijo si conocía Urueña. Y sí que lo conocía pues en el año 7I un realizador de TVE me trajo aquí a cantar un villancico para un programa de Navidad. El pueblo en ese momento era una ruina total. El presidente de la Diputación de entonces había comprado una casa en Urueña para hacer un parador, pero como ocurre siempre, el siguiente en ocupar el cargo cambió los planes, la casa quedó a medio restaurar y no se hizo el parador. En el 87, me dijeron, «piensa a ver qué se puede hacer aquí» y a mí se me encendió la luz, pues pensé que el museo, en Valladolid, sería el último y, sin embargo, en Urueña, sería el primero. Así que me vine aquí con la bronca de Miguel Delibes que me dijo «te vas a hundir en un pueblo» (conservo sus cartas); yo pensé que si me lo decía Delibes, el amante de todo rural, de los pueblos... a lo mejor me estaba equivocando. Además, me dejó perplejo, pues luego, cuando todo empezó a funcionar, vino a comer un día y me dijo que él se había equivocado en su primera apreciación.

Lo que pretendí es que se conociera lo que hacíamos aquí, lo que queríamos crear. Le pedí a los amigos periodistas si podían hacer reportajes para darnos a conocer... y así empezamos.

P. Volvamos a la parte pedagógica, porque recomponiendo la memoria colectiva, desde el punto de vista de algunos referentes de la Institución Libre de Enseñanza (ILE), por ejemplo, Antonio Machado, Giner de los Ríos, Cossío eran unos apasionados de la recuperación y el reconocimiento del folklore en todas sus dimensiones, en lo musical, lo expresivo, lo dramático, lo cultural y de ir incorporándolo en la sensibilización estética y pedagógica de los niños de la ILE y, posteriormente, en el sistema educativo.

R. Sí, aquí vienen muchas personas del Instituto Escuela, gente mayor que tienen el recuerdo de haber cantado esas canciones de pequeños, en su infancia, y tienen un recuerdo imborrable. También de las Misiones Pedagógicas y de las Cátedras de la Sección Femenina; de esto tengo dos opiniones, una positiva y otra negativa; negativas en el sentido de que Misiones Pedagógicas, y de las Cátedras de la Sección Femenina que lo copiaron, pretendían con cierta soberbia imponer su cultura a un grupo que tenía una cultura propia, que probablemente no lo mostraban. Esas personas que tenían esa cultura puede que ni siquiera supieran escribir, pero tenían una percepción del mundo muy completa. De hecho, la razón por la que la ILE y otras instituciones parecidas veían muy útil el uso del folklore y la tradición es porque en realidad van siempre muy unidos a la persona, no se puede separar. Yo siempre digo a las personas que vienen aquí a estudiar un tema concreto que nada se produce aisladamente en la vida, todo tiene una relación que se junta en una persona. Por eso quien elige un repertorio no lo hace por capricho, lo elige porque le está transmitiendo algo que conecta con su manera de pensar y actuar; algunas veces se corresponde con lo que los padres o abuelos nos 
enseñaban en la cocina y otras veces dan un paso más allá; pero nunca podemos estudiar un hecho o una expresión popular sin tener en cuenta el contexto unido a cada una de las personas que van a mantener viva la memoria. Creo que este es un tema que interesa a quien quiere que los niños tengan contacto con el mundo. Por eso, las Misiones Pedagógicas hicieron mucho bien, pues llevaban elementos nuevos de la gente que vivía en la ciudad.

Pero hoy día, cuando empiezas a darte cuenta de lo que hemos avanzado y retrocedido en la sociedad ves que existe un problema importante que consiste en controlar a un turismo depredador que está machacando la tradición. La solución pasa por que los padres, profesores o las agencias de viajes expliquen previamente la importancia y la fragilidad de lo que van a ver, pues esas personas tienen una cultura muy sólida e importante, frente a nosotros que a veces la tenernos de barniz. Quien tenía un oficio y lo sabía practicar conocía un mundo muy completo, por ejemplo, los pastores que debían saber muchas cosas o los trashumantes que eran gente cultísima.

P. Esta impresionante estructura que has creado o la Revista de Folklore ¿qué tipo de receptividad tiene en los sectores académicos, departamentos de antropología, de historia, de educación?

R. Nosotros tenemos un seguimiento de los posibles lectores de la revista a través de las estadísticas de internet. Cuando editábamos en papel sabíamos el número exacto de ejemplares que hacíamos y a quién iba dirigido. Ahora, sí sabemos que los visitantes son un millón de personas al año, que buscan, por lo general, un tema concreto porque están trabajando en él o por curiosidad; los hay que leen el artículo entero pues las estadísticas nos dicen el tiempo que están en la página y que estén más de un minuto y medio indica que sí que hay lectura.

Tenemos relación con universidades y con centros de investigación, más de 300 centros de todo el mundo; entre ellos, mantenemos mucha relación en el mundo hispánico, en particular en Chile, Argentina, Venezuela y en Brasil, en este último, especialmente, por el tema de los Pliegos de Cordel pues allí se usan mucho, siguen vivos ya que el comportamiento humano es el mismo que en la época medieval quitando los ropajes y las espadas.

P. Esta revista se dirige de forma preferente, aunque no exclusivamente, a historiadores de Historia de la Educación ¿qué sugerencia les harías desde tu rica experiencia en el campo de la etnografía, el folklore, la cultura popular?

R. Yo, para investigar, siempre he necesitado la pregunta, la curiosidad es fundamental. Por tanto, considero básico el saber orientar a los niños hacia unos aspectos en los que ellos vayan mejorando en el criterio. Es el aprendizaje por descubrimiento, fundamental en educación. A lo largo del tiempo he tenido muchas experiencias y veo reflejo de ellas en estudios que otros han hecho. Lo fundamental es la curiosidad y preguntar y, por supuesto, saber responder. 
P. Y para los expertos o responsables de la Administración, ¿qué sugerencias tienes para que su gestión pueda llegar al día a día de las escuelas y de los maestros?

R. Yo siempre que me he acercado al mundo real de la escuela he percibido que, a veces, se pierde mucho tiempo en esfuerzos que no tienen que ver con la educación entendida como la transmisión de conocimientos, pero supongo que es consecuencia de que es un sistema que necesita un orden y unas normas. Hace unos años, estuve como experto para hacer el currículo de la LOCE y tenía que rebobinar pues no entendía nada, el lenguaje educativo es muy oscuro para los que no estamos dentro, se buscan patrones que sirvan para todo el currículo, pero yo quería aportar frescura a ese mundo, a pesar de mi escasa capacidad para dar consejos, es algo que me supera. Yo también los busco, pero busco mi propio sistema para encontrar las cosas y comprenderlas, para relacionar comportamientos humanos... y esto es lo que creo que se debe hacer con la educación.

La educación en el medio rural dependía de los padres y los abuelos, se recibía en la familia a base de experiencias. Cuando he entrevistado a personas del mundo rural ves cómo esta ha visto la vida y te dices a ti mismo ¡vaya educador que se ha perdido el mundo!, a las preguntas que yo les hacía me respondían de forma perfecta, me daban lecciones, había gente muy buena, muy preparada y dentro de cada familia había una forma de ser, de comportarse y de entender el mundo.

P. Esta manera que muestras de tolerancia, de respeto, de aproximación, de entender al interlocutor es el punto de partida básico del etnógrafo, del historiador de la educación, del investigador social.

R. Sí, pero yo, desgraciadamente, no lo he visto mucho entre compañeros; más de una vez, me he sentido incomodo en estas entrevistas cuando alguien quiere seguir y seguir preguntando a pesar de estar con una persona mayor que se cansa: «ihombre, vamos a esperar a mañana que no se va a morir hoy y si quiere que conteste y si no quiere pues nada!, ¡si no se acuerda, déjale!». Es necesario mantener ese respeto y también al preguntar. Reconozco que he sido un poco raro y seguro que por ello me he perdido información.

P. La escuela rural se está muriendo, todos los años se cierran unas cuantas escuelas, ¿cómo ves el problema de la despoblación?

R. Veo mal el tema de la despoblación y del turismo rural; son dos cuestiones que están presentes desde los años 60 y no ha habido voluntad política de hacer nada, es más cómodo dejar que se mueran. Esta es una de las cosas que me planteé cuando aceptaron que pusiera el Centro Etnográfico en Urueña: yo tenía que estar aquí. Por esos días escribía en El Norte de Castilla las «Cartas desde Urueña» para evitar desvincularme del mundo de la ciudad, como me decía Miguel Delibes, y una de ellas le sentó muy mal a la maestra, al alcalde y al cura, pues les criticaba que no vivían aquí. 
Existe una idea muy repetida en las familias de agricultores, que mi hijo vaya a Valladolid a estudiar abogado o lo que sea, y no les dicen a sus hijos que tienen una empresa de agricultura desde hace 400 años en la que pueden continuar. Es consecuencia de que el campo ha estado muy unido al sacrificio y a la pobreza, pero hoy día, ni es tan duro ni es tanta la pobreza. En los años 50 pensaban que la solución era la huida a la capital, ya se ha visto que no lo era, pero hoy día no tiene sentido; yo le digo a mis vecinos que consideren la continuidad en la agricultura, pero la aspiración actual es otra, están en otra escala de valores.

P. Desde tu experiencia e investigaciones y sin ánimo de convertirme en la investigadora que no respeta el tiempo del entrevistado, ¿ consideras que hay vinculaciones ideológicas o políticas entre el folklorismo y los nacionalismos o los fascismos que se amparan en los valores de la tradición?

R. Si te remontas a Herder y a otros filósofos alemanes, te das cuenta de que los primeros nacionalismos surgen con la necesidad de que la nación exista, tenga unos límites y tenga un pasado cuanto más antiguo mejor, esa necesidad se produce a partir del siglo XVII y es el momento en que nacen los nacionalismos que se basan, casi siempre, en leyendas falsas e indemostrables.

Esto lo comenté con Caro Baroja que tenía un estudio magnífico Las Mistificaciones en la Historia en las que hablaba de cómo la prehistoria española se la inventó el dominico Annio de Viterbo para complacer a los Reyes Católicos, y esta prehistoria no hay manera de demostrarla. Cuando hay que investigar e ir a la arqueología se comprueba que nada coincide, son leyendas indemostrables.

Los inventos de algunas naciones del siglo XIX, XX y XXI son así, se usa el patrimonio histórico y la tradición para lo que a cada uno le va bien y le interesa. Es una utilización, hay muchos elementos que distorsionan la historia, indemostrables y que solo se usan con intereses espurios. Esto se usó en el fascismo y el nazismo con la ascendencia de Herder; buscaban elementos mitológicos y los unían al pasado de una nación con un mundo lleno de leyenda y mitología; es de donde reaparecen muchas leyendas que ya existían. La leyenda y el mito a veces son necesarios en los pueblos como soporte, el problema es cuando se lleva al terreno de la imposición y de crear un mundo falso. Esto ya no me parece bien.

Muchas gracias, Joaquín, ha sido un placer y una oportunidad extraordinaria estar y compartir contigo. 